3. Hsiang HW, Ohno-Matsui K, Shimada N, et al. Clinical characteristics of posterior staphyloma in eyes with pathologic myopia. Am J Ophthalmol 2008;146(1):102-110.

4. Kim MJ, Lee EJ, Kim TW. Peripapillary retinal nerve fibre layer thickness profile in subjects with myopia measured using the Stratus optical coherence tomography. Br J Ophthalmol 2010;94(1):115-120.

5. Kang SH, Hong SW, Im SK, et al. Effect of myopia on the thickness of the retinal nerve fiber layer measured by Cirrus HD optical coherence tomography. Invest Ophthalmol Vis Sci 2010;51(8):4075-4083.

\section{The Rate of Progression and Ocular Perfusion Pressure in the Low- Pressure Glaucoma Treatment Study}

\section{EDITOR:}

THE LOW-PRESSURE GLAUCOMA TREATMENT STUDY IS THE first multicenter, randomized, double-masked, controlled clinical trial comparing the efficacy of topical twice-daily brimonidine tartrate $0.2 \%$ and twice-daily timolol maleate $0.5 \%$ in reducing intraocular pressure (IOP) to prevent or delay visual field progression in patients with low-pressure glaucoma, more commonly called normal-tension glaucoma (NTG). ${ }^{1}$

In our opinion, some considerations have to be taken into account before claiming its findings will change our clinical practice. Eligibility of patients based on IOP was assessed throughout a diurnal curve, with no IOP measurement taken at nighttime or at least in supine position. Exclusion of false diagnosis of NTG with IOP values of more than $21 \mathrm{~mm} \mathrm{Hg}$ during either daytime or nighttime is mandatory in clinical and therapeutic studies, because it accounts for between $11 \%$ and $20 \%$ of the suspected cases of NTG. ${ }^{2}$

NTG is a group of progressive optic neuropathies sharing a slow progressive degeneration of retinal ganglion cells and their axons, resulting in typical optic disc damage, visual field defects compatible with the glaucomatous cupping, and progression of the disease. The requirement that the disease be progressive is controversial. NTG usually is a progressive disease, although this may not be manifest for several years. Nevertheless, the progressive nature of the disease always should be borne in mind, because this will help to distinguish true NTG from an isolated ischemic event that may mimic it in terms of optic disc and visual field appearances. ${ }^{3}$ The authors made no mention of the rate of progression of the patients before randomization, nor if this variable was evaluated at the baseline, to take it into account in the design (ie, stratified randomization) or in the statistical analysis.

Moreover, we previously showed that both timolol and brimonidine are able to reduce blood pressure throughout a 24-hour period in primary open-angle glaucoma (POAG) patients ${ }^{4}$; thus, in patients affected by NTG, because of an abnormal vascular autoregulatory system, the use of these 2 drugs should be avoided so as not to induce further reduction of ocular perfusion pressure and greater fluctuations. ${ }^{5}$

Beyond the clinical considerations, the survival analysis is flawed by not taking into account the effect of competitive risk on the correct estimation of the relative efficacy of the treatments. In fact, the authors mentioned that 36 patients $(37 \%)$ assigned to brimonidine and 8 patients (10\%) to timolol dropped out within 1 year from randomization mainly for reasons related to study treatments, such as allergy or low compliance. The lack of following up these patients until the end of the study compromises the correct interpretation of the efficacy results. Supportive analyses by using a composite end point, such as time to treatment failure for any cause, and a competitive risk analysis $^{6}$ would have been of help to facilitate the text comprehension and to increase the strength of the results.

LUCIANO QUARANTA

Brescia, Italy

IRENE FLORIANI

Milano, Italy

Conflict of Interest Disclosures: The authors have completed and submitted the ICMJE Form for Disclosure of Potential Conflicts of Interest and none were reported.

\section{REFERENCES}

1. Krupin T, Liebman JM, Greenfield DS, Ritch R, Gardiner S. A randomized trial of brimonidine versus timolol in preserving visual function: results from the low-pressure glaucoma treatment study. Am J Ophthalmol 2011;151(4):671-681.

2. Renard E, Palombi K, Gronfier C, et al. Twenty-four hour (Nyctohemeral) rhythm of intraocular pressure and ocular perfusion pressure in normal-tension glaucoma. Invest Ophthalmol Vis Sci 2010;51(2):882-889.

3. Kamal D, Hitchings R. Normal tension glaucoma-a practical approach. Br J Ophthalmol 1998;82(7):835-840.

4. Quaranta L, Gandolfo F, Turano, et al. Effects of topical hypotensive drugs on circadian IOP, blood pressure, and calculated diastolic ocular perfusion pressure in patients with glaucoma. Invest Ophthalmol Vis Sci 2006;47(7):2917-2923.

5. Sung KR, Cho JW, Lee S, et al. Characteristics of visual field progression in medically treated normal-tension glaucoma patients with unstable ocular perfusion pressure. Invest Ophthalmol Vis Sci 2011;52(2):737-743.

6. Prentice RL, Kalbfleisch JD, Peterson AV Jr, Flournoy N, Farewell VT, Breslow NE. The analysis of failure times in the presence of competing risks. Biometrics 1978;34(4),541-554.

\section{REPLY}

WE THANK DRS QUARANTA AND FLORIANI FOR THEIR interest in our publication. ${ }^{1}$ The Low-pressure Glaucoma Treatment Study (LoGTS) is a randomized trial of the effect of brimonidine versus timolol on preserving visual function in patients with low-pressure glaucoma. The 